\title{
Treatment Options for Novel Corona Virus-Current guidelines in Clinical Settings of Pakistan
}

\section{Nayab Mustansar* and Rizwan Rafi}

Consultant Nuclear Physician, Department of Nuclear Medicine, Islamabad, Pakistan *Corresponding Author: Nayab Mustansar, Consultant Nuclear Physician, Department of Nuclear Medicine, Islamabad, Pakistan.
Received: April 30, 2020

Published: May 02, 2020

(C) All rights are reserved by Nayab

Mustansar and Rizwan Rafi.

\begin{abstract}
As of February 2020, new cases of COVID19 have been reported in Pakistan, Sindh province initially and then spread to the rest of provinces due to the Foreigners coming back to Pakistan [1]. At present unfortunately no vaccine has been developed moreover we don't have any specific anti-viral for this novel corona virus [2-4]. Three general methods, which include existing broad-spectrum antiviral drugs using standard assays, screening of a chemical library containing many existing compounds or databases, and the redevelopment of new specific drugs based on the genome and biophysical understanding of individual coronaviruses, are used to discover the potential antiviral treatment of human pathogen coronavirus [5-8].

Although till now the patients are being treated on symptomatic basis. Moreover, immune boosting drugs and diet has also been added and have shown positive results too.
\end{abstract}

Keywords: Treatment; Analgesics; Antibiotics; Antivirals; Immune Boosters; Coronavirus; Pneumonia

\section{Introduction}

This new virus seems to be very contagious and has quickly spread globally [9]. The symptoms include mostly due to affecting the respiratory system. The common symptoms include cough, breathing difficulty, dyspnea, fever, Myalgia and GIT symptoms at times are reported as well [10].

The only investigation available till now is PCR to calculate the count of virus (Viral Load). Moreover, the COVID-19 specifically causes opacities in lungs so Chest $\mathrm{X}$-rays are also being done to rule out other diseases from COVID-19 pneumonia [11-13].

Different countries are trying different treatments as per the patient symptoms as vaccine is still a dream. It has been reported further that Virus has many mutant forms till now so preparing vaccine is a big job and will be a breakthrough in the field of medicine [14].

\section{Treatment options}

Most countries are utilizing some type of clinical and epidemiologic information to determine who should have testing performed. In the United States, criteria have been developed for persons under investigation (PUI) for COVID-19. According to the U.S. CDC, most patients with confirmed COVID-19 have developed fever and/or symptoms of acute respiratory illness (e.g. cough, difficulty breathing). If a person is a PUI, it is recommended that practitioners immediately put in place infection control and prevention measures. Initially, they recommend testing for all other sources of respiratory infection. Additionally, they recommend using epidemiologic factors to assist in decision making. There are epidemiologic factors that assist in the decision on who to test. This includes anyone who has had close contact with a patient with laboratory- confirmed COVID-19 within 14 days of symptom onset or a history of travel from affected geographic areas (China, Italy, Iran, Japan, and South Korea) within 14 days of symptom onset $[15,16]$.

In Pakistan although Triage system has been introduced in which the patients are label as per severity of symptoms. Mild cases are treated by isolating them either at home or at hospitals for 14 days. Moderate cases with cough and fever are treated with antipyretics and analgesics. However, the severe cases with respiratory difficulty are put on ventilators. If patient has developed pneumonia then the antibiotic treatment (Azomax - Azithromycin) was given to the patient [17].

The treatment up till now is not definitive few trials with Resochin have been carried out and the results were variable, few patients did respond while the others didn't [18].

\section{Conclusion}

The vaccine for the COVID-19 is still under trials. The definitive treatment hasn't been found yet.

We are losing so many precious lives on daily basis by this unseen virus.

Although currently the treatment trials have shown that pneumonia due to COVID 19 is responding to azithromycin and Resochin. However, for severe dyspnea the ventilator support is still the last resort.

The trials of Serum of recovered patients is still a question mark in the treatment of this deadly virus. Hopefully in the couple of weeks or months some break through treatment will emerge. 


\section{Bibliography}

1. National Health Commission of the People's Republic of China. "Pneumonia epidemic situation of new coronavirus infection" (2020).

2. Natsuko Imai. "Report 2: Estimating the potential total number of novel Coronavirus cases in Wuhan City, China” (2020).

3. Lu H., et al. "Outbreak of Pneumonia of Unknown Etiology in Wuhan China: the Mystery and the Miracle". Journal of Medical Virology 92.4 (2020): 401-402.

4. Kim Y., et al. "Reversal of the Progression of Fatal Coronavirus Infection in Cats by a Broad-Spectrum Coronavirus Protease Inhibitor". PLoS Pathogen 12.3 (2016): e1005531.

5. Channappanavar R., et al. "Sex-Based Differences in Susceptibility to Severe Acute Respiratory Syndrome Coronavirus Infection". Journal of Immunology 198.10 (2017): 4046-4053.

6. Zumla A., et al. "Coronaviruses-drug discovery and therapeutic options”. Nature Reviews Drug Discovery 15.5 (2016): 327 347.

7. National Health Commission of the People's Republic of China. Notice on printing and distributing the diagnosis and treatment plan of pneumonia with new coronavirus infection (trial version 3) (2020).

8. Chu CM., et al. "Role of lopinavir/ritonavir in the treatment of SARS: initial virological and clinical findings". Thorax 59.3 (2004): 252-256.

9. Arabi YM., et al. "Treatment of Middle East Respiratory Syndrome with a combination of lopinavir-ritonavir and interferon- $\beta 1 \mathrm{~b}$ (MIRACLE trial): study protocol for a randomized controlled trial". Trials 19.1 (2018): 81.

10. Wang Y., et al. "Comparative effectiveness of combined favipiravir and oseltamivir therapy versus oseltamivir monotherapy in critically ill patients with influenza virus infection". Journal of Infectious Diseases 221.10 (2019): 1688-1698.

11. Sheahan TP., et al. "Comparative therapeutic efficacy of remdesivir and combination lopinavir, ritonavir, and interferon beta against MERS-CoV". Nature Communications 11.1 (2020): 222.

12. Agostini ML., et al. "Coronavirus Susceptibility to the Antiviral Remdesivir (GS-5734) Is Mediated by the Viral Polymerase and the Proofreading Exoribonuclease". mBio 9.2 (2018): e00221-18.

13. Chow EJ., et al. "Influenza virus-related critical illness: prevention, diagnosis, treatment". Critical Care 23.1 (2019): 214.

14. Bleibtreu A., et al. "Clinical management of respiratory syndrome in patients hospitalized for suspected Middle East respiratory syndrome coronavirus infection in the Paris area from 2013 to 2016". BMC Infectious Diseases 18 (2018): 331.
15. Xia S., et al. "A pan-coronavirus fusion inhibitor targeting the HR1 domain of human coronavirus spike". Science Advances 5.4 (2019): eaav4580.

16. Coleman CM., et al. "Abelson Kinase Inhibitors Are Potent Inhibitors of Severe Acute Respiratory Syndrome Coronavirus and Middle East Respiratory Syndrome Coronavirus Fusion". Journal of Virology 90.19 (2016): 8924-8933.

17. Ji S., et al. "Unique synergistic antiviral effects of Shufeng Jiedu Capsule and oseltamivir in influenza A viral-induced acute exacerbation of chronic obstructive pulmonary disease". Biomedicine and Pharmacotherapy 121 (2020): 109652.

18. Ding Y., et al. "The Chinese prescription lianhuaqingwen capsule exerts anti-influenza activity through the inhibition of viral propagation and impacts immune function". BMC Complementary and Alternative Medicine 17.1 (2017): 130.

\section{Assets from publication with us}

- Prompt Acknowledgement after receiving the article

- Thorough Double blinded peer review

- Rapid Publication

- Issue of Publication Certificate

- High visibility of your Published work

Website: www.actascientific.com/

Submit Article: www.actascientific.com/submission.php Email us: editor@actascientific.com

Contact us: +91 9182824667 